JURNAL KACAPURI

JURNAL KEILMUAN TEKNIK SIPIL

Volume 3 Nomor 2 Edisi Desember 2020

\title{
TEKNIK PENGAMBILAN KEPUTUSAN PADA PENENTUAN SKALA PRIORITAS PEMELIHARAAN KONDISI FISIK WADUK TIRTOMARTO DENGAN APLIKASI ANALYTICAL HIERARCHY PROCESS DAN EXPERT CHOICE 11
}

\author{
Aan Andriawan \\ Dosen Program Studi Teknik Sipil, Fakultas Teknik Sipil Dan Perencanaan, \\ Universitas Internasional Batam \\ E-mail: aan@uib.ac.id/Hp+6282223338706
}

\begin{abstract}
ABSTRAK
Berita runtuhnya Situ Gitung pada tanggal 27 Maret 2009 sekitar pukul 04.30 WIB dengan korban jiwa lebih dari 100 jiwa, telah menghentakkan kita semua. Meskipun bendungan atau tanggulnya rendah, namun disamping manfaatnya yang besar situ tersebut menyimpan daya rusak yang sedemikian hebatnya. Peristiwa jebolnya Bendungan Situ Gintung merupakan kegagalan dalam kegiatan pemeliharaan bendungan. Hal ini menunjukkan pentingnya penilaian kondisi fisik pada setiap komponen bendungan. Penelitian ini mengambil lokasi di Waduk Tirtomarto Kabupaten karanganyar Provinsi Jawa Tengah. Metode dalam studi ini adalah deskriptif kuantitatif dengan menggunakan data primer dan data sekunder. Tahapan dalam penelitian ini yaitu dengan inventarisasi dan analisis kerusakan, penyesuaian penilaian kondisi fisik bendungan yang ada dengan kondisi di lokasi penelitian, analaisis penilaian kondisi Waduk Tirtomarto, analisis penentuan penanganan pemeliharaan yang baik dengan menggunakan aplikasi Analytical Hierarchy Process dan Expert Choice 11 versi trial. Dari analisa penilaian kondisi fisik didapatkan hasil 92,69\% dengan hasil tersebut maka kondisi Bendungan Delingan pada Tahun 2019 dinyatakan dalam kondisi Baik. Analisa aplikasi Analytical Hierarchy Process dan Expert Choice 11 juga didapatkan prioritas penanganan pemeliharaan Waduk Tirtomarto adalah bangunan pengambilan. Bangunan Pengambilan menempati peringkat teratas dari hasil analisa program berdasarkan kriteriakriteria yang telah ditetapkan. Penanganan pemeliharaan bangunan pengambilan sebagai prioritas utama diharapkan dapat menjadikan kinerja Waduk Tirtomarto dapat optimal.
\end{abstract}

\section{Kata kunci : Bendungan, Pemeliharaan Bendungan, Penilaian Kondisi Fisik Bendungan, AHP, Expert Choice}

\section{ABSTRACT}

The news of Situ Gintung (Gintung Lake) collapse on March 27, 2009 at 04.30 Local Time with more than 100 life tolls has stricken all of us. Because of its low dam/embankment, in addition to having large benefit, it stores a great destruction power. The collapse of Situ Gintung (Gintung Lake) was due to the damaged dam condition. The dam damage is the failure of dam maintenance. It indicates the importance of dam condition assessment over times. This research was taken place in Tirtomarto Dam located in Karanganyar Regency Central Java Province. The method applied in this study was a descriptive qualitative one using primary and secondary data. Stages in this study is to inventory and damage analysis, valuation adjustments to the physical condition of the existing dam with the conditions at the site of the research, analysis Tirtomarto Dam condition assessment, analysis using Analytical Hierarchy Process (AHP), analytical determination good maintenance treatment using Expert Choice program 11 trial version. Assessment of physical condition Tirtomarto Dam after 92, 69\% value obtained was 
JURNAL KACAPURI

JURNAL KEILMUAN TEKNIK SIPIL

Volume 3 Nomor 2 Edisi Desember 2020

analyzed (good). Analysis of the application of Hierarchy Process and Expert Choice 11 also obtained priority in handling the maintenance of Tirtomarto Dam, namely the retrieval building. The Retrieval Building occupies the top rank from the results of the Tirtomarto Dam.

Keywords: Dams, Maintenance of Dams, Dams Physical Condition Assessment, AHP, Expert Choice

\section{PENDAHULUAN}

Manusia telah mengembangkan bendungan sejak ribuan tahun yang lalu untuk memenuhi kebutuhan air bagi berbagai kepentingan. Diseluruh dunia sejak tahun lima puluhan, pembagunan bendungan yang diprakrasai oleh kalangan pemerintah dan sektor swasta mengalami pertumbuhan yang sangat pesat sejalan dengan pertumbuhan penduduk dan ekonomi. Lebih kurang 45.000 bendungan besar telah dibangun untuk tujuan tersebut diatas. Di Indonesia saat ini ada kira-kira 120 bendungan yang dikelola oleh Kementrian PUPR, PLN dan pihak swasta dibidang pertambangan maupun kalangan lainnya. Dilihat dari penyebarannya sebagian besar bendungan-bendungan tersebut terletak di Pulau Jawa, Bali, Lampung, Sulawesi Selatan, Kalimantan Selatan dan Timur, Nusa Tenggara Barat dan Nusa Tenggara Timur. Di Kecamatan Karanganyar, Kabupaten Karanganyar ada Bendungan yang dibangun Pemerintah Belanda mulai tahun 1920 dan selesai pada tahun 1923 yaitu Waduk Tirtomarto atau lebih dikenal dengan nama Bendungan Delingan. Secara geografis, Bendungan Delingan berada pada koordinat $7^{\circ}$ 35'14, 60" LS dan $110^{\circ}$ 59'22, 60” BT. Berdasarkan sistem Wilayah Sungai, Bendungan Delingan masuk ke dalam Wilayah Sungai Bengawan Solo, dan DAS Bengawan Solo. Saat ini pengelolaan Bendungan Delingan dikelola oleh BBWS Bengawan Solo. Penilaian kondisi bendungan diperlukan untuk mengetahui tingkat keamanan bendungan dan sebagai bahan pertimbangan untuk kegiatan rehabilitasi bendungan. Berdasarkan permasalahan tersebut diatas maka perlu dilakukan penilaian kondisi fisik Waduk Tirtomarto, yang dapat digunakan dalam penelitian.

\section{KAJIAN PUSTAKA}

Dony Adzan (2008) mengemukakan bahwa monitoring, pemeliharaan instrument dan bangunan pelengkap di bendungan adalah penting, agar fungsi bangunan dapat optimal kembali. Hal ini dapat dilakukan dengan melakukan kegiatan operasi dan pemeliharaan bendungan. Salah satu kegiatan tersebut adalah melakukan penilaian kondisi fisik bendungan secara rutin. 
JURNAL KACAPURI

JURNAL KEILMUAN TEKNIK SIPIL

Volume 3 Nomor 2 Edisi Desember 2020

Edwin Prasetya K (2016) melakukan analisis penentuan daerah prioritas perbaikan saluran drainase di Kelurahan Kadipiro bagian barat menggunakan metode Analytic Network Process (ANP). Kriteria yang ditinjau pada meliputi: krieria genangan, kerugian fasilitas transportasi, kerugian fasilitas ekonomi, kerugian fasilitas sosial dan pemerintah, kepadatan penduduk. Berdasarkan hasil analisis diperoleh J1. Ki Mangun Sarkoro menjadi daerah prioritas perbaiakan saluran drainase di Kelurahan Kadipiro bagian Barat. Herlen (2009 ) menjelaskan bahwa tujuan pengelolaan bendungan adalah untuk mencegah timbulnya resiko dari kerusakan bendungan.. M. Marzulian Ramli dan Bambang E. Yuwono, (2015) untuk meminimalisir terjadinya kegagalan dalam pengoperasian waduk harus ada pengelolaan waduk yang maksima.

\section{DASAR TEORI}

\section{Penilaian Kondisi Fisik Bendungan}

Dalam Pedoman Penilaian Kondisi Fisik Bendungan beserta Waduknya yang dikeluarkan atau diterbitkan oleh Balai Bendungan pada tahun 2010. Pedoman ini mengatur mengenai tata cara penilaian dan langkah-langkah dalam penilaian Bendungan beserta Waduknya. Dalam pemeliharaan bendungan yang baik dan benar diperlukanlah penilaian kondisi suatu bendungan yang tertuang dalam Pedoman Penilaian Kondisi Fisik Bendungan yang mengacu pada Peraturan Pemerintah Nomor 37 Tahun 2010, tentang Bendungan.

\section{Komponen Yang dinilai}

Penilaian Kondisi fisik bendungan beserta waduknya dilakukan pada beberapa komponen, yaitu:

1. Waduk, dengan bagian-bagian yang dilakukan penilaian antara lain: a) Sedimentasi, b) Daerah Sempadan Waduk, c) Daerah Sabuk Hijau, dan d) Inflow Waduk.

2. Tubuh Bendungan, bagian-bagiannya yang dilakukan penilaian adalah sebagai berikut: a) Lereng Hilir, b) Puncak Bendungan, c) Lereng Hulu, d) Bidang Tumpuan, dan e) Rembesan.

3. Bangunan Pelengkap, yang bagian-bagiannya yang dilakukan penilaian adalah sebagai berikut: a) Bangunan Pengambilan, b) Bangunan Pengeluaran, dan c) Bangunan Pelimpah. 
JURNAL KACAPURI

JURNAL KEILMUAN TEKNIK SIPIL

Volume 3 Nomor 2 Edisi Desember 2020

4. Instrumen Bendungan, alat-alat instrumentasi di bendungan yang perlu dilakukan penilaian adalah sebagai berikut: a) Pengukur Rembesan, b) Pengukur Tekanan Pori, c) Pengukur Pergerakan, dan d) Sumur Pengamatan.

\section{Pembobotan Penilaian}

Pembobotan tiap komponen dan sub komponen pada penlaian kondisi fisik bendungan adalah sebagai acuan dalam menghitung indeks kerusakan pada tiap komponen dan sub komponen di bendungan. Kontribusi nilai bobot tiap komponen terhadap kondisi keseluruhan fisik bendungan beserta waduknya tidak sama, bobot tiap komponen disusun berdasarkan besarnya pengaruh komponen tersebut terhadap fungsi pelayanannya dan pertimbangan terhadap kegagalan bangunan, Komponen dan bobot penilaian pada setiap bendungan beserta waduknya menurut Standart Pedoman Penilaian Kondisi Fisik Bendungan dapat dilihat pada Tabel 1.

Tabel 1. Komponen dan Pembobotan Penilaian Kondisi Fisik Bendungan Beserta Waduknya

\begin{tabular}{|c|c|c|c|c|}
\hline No & Kriteria & $\begin{array}{c}\text { Bobot } \\
(\%)\end{array}$ & Sub Kriteria & $\begin{array}{c}\text { Bobot } \\
(\%)\end{array}$ \\
\hline \multirow[t]{3}{*}{1} & \multirow[t]{3}{*}{ Waduk } & \multirow[t]{3}{*}{10} & Sedimentasi & 3 \\
\hline & & & Daerah Sabuk Hijau & 3 \\
\hline & & & Inflow Waduk & 4 \\
\hline \multirow[t]{4}{*}{2} & \multirow{4}{*}{$\begin{array}{c}\text { Tubuh } \\
\text { Bendungan }\end{array}$} & \multirow[t]{4}{*}{40} & Lereng Hulu & 10 \\
\hline & & & Puncak & 10 \\
\hline & & & Lereng Hilir & 10 \\
\hline & & & Rembesan Bangunan & 10 \\
\hline \multirow[t]{3}{*}{3} & \multirow{3}{*}{$\begin{array}{l}\text { Bangunan } \\
\text { Pelengkap }\end{array}$} & \multirow[t]{3}{*}{40} & Pengambilan & 10 \\
\hline & & & $\begin{array}{l}\text { Bangunan } \\
\text { Pengeluaran }\end{array}$ & 10 \\
\hline & & & Bangunan Pelimpah & 20 \\
\hline \multirow[t]{3}{*}{4} & \multirow[t]{3}{*}{ Instrumentasi } & \multirow[t]{3}{*}{10} & $\begin{array}{l}\text { Pengukur Tekanan } \\
\text { Pori }\end{array}$ & 4 \\
\hline & & & Pengukur Pergerakan & 3 \\
\hline & & & Sumur Pengamatan & 3 \\
\hline & umlah & 100 & & 100 \\
\hline
\end{tabular}

Sumber: Pedoman Penilaian Kondisi Fisik Bendungan (2010) 
JURNAL KACAPURI

JURNAL KEILMUAN TEKNIK SIPIL

Volume 3 Nomor 2 Edisi Desember 2020

\section{Indexs Bobot Kerusakan}

Klasifikasi penilaian kondisi sitentukan berdasrkan pada permasalahan dan tingkat kerusakan bendungan beserta waduknya. Adapun klasifikasi penilaian kondisi dapat dilihat pada Tabel 2.

Tabel 2 Nilai Kondisi komponen waduk

\begin{tabular}{ll|l}
\hline No. & Kondisi & \multicolumn{1}{|c}{ Penjelasan } \\
\hline 1 & Baik & $\begin{array}{l}\text { Jika nilai kondisi }>90 \% \text { dan nilai tingkat kerusakan } \\
<10 \% \text { dari kondisi awal bangunan. }\end{array}$ \\
\hline 2 & Rusak ringan & $\begin{array}{l}\text { Jika nilai kondisi } 80-89 \% \text { dan nilai tingkat } \\
\text { kerusakan } 10-20 \% \text { dari kondisi awal bangunan. }\end{array}$ \\
\hline 3 & Rusak sedang & $\begin{array}{l}\text { Jika nilai kondisi 60-79\% dan nilai tingkat } \\
\text { kerusakan 21-40\% dari kondisi awal bangunan. }\end{array}$ \\
\hline 4 & Rusak berat & $\begin{array}{l}\text { Jika nilai kondisi }<60 \% \text { dan nilai tingkat kerusakan } \\
>40 \% \text { dari kondisi awal bangunan. }\end{array}$ \\
\hline
\end{tabular}

Sumber: Pedoman Penilaian Kondisi Bendungan 2010

\section{Skala Prioritas}

AHP (Analytical Hierarchy Process) merupakan sebuah hirarki fungsional dengan input utamanya persepsi manusia. Suatu masalah yang kompleks dan tidak terstruktur dipecah ke dalam kelompok-kelompok kemudian diatur menjadi suatu bentuk hierarki (Saaty, 1998). AHP dapat menata bagian atau variabel ini dalam suatu susunan hirarki, memberi nilai numerik pada pertimbangan subjektif tentang pentingnya tiap variabel dan mensintesis berbagai pertimbangan untuk menetapkan variabel mana yang memiliki prioritas paling tinggi dan bertindak untuk mempengaruhi hasil pada situasi tersebut.

Metode AHP ini membantu memecahkan persoalan yang kompleks dengan menstruktur suatu hirarki kriteria dan menarik berbagai pertimbangan guna mengembangkan bobot atau prioritas. Metode ini juga menggabungkan kekuatan perasaan dan logika yang bersangkutan pada berbagai persoalan, lalu mensintesis berbagai pertimbangan yang beragam menjadi hasil yang cocok dengan perkiraan kita secara intuitif sebagaimana yang dipresentasikan pada pertimbangan yang telah dibuat (Saaty, 1994). Menurut Saaty, ada beberapa prinsip dalam memecahkan persoalan dengan AHP, yaitu prinsip menyusun hirarki (Decompostion), prinsip menentukan prioritas (Comparative Judgement), dan prinsip konsistensi logis (Logical Consistensy). 
JURNAL KACAPURI

JURNAL KEILMUAN TEKNIK SIPIL

Volume 3 Nomor 2 Edisi Desember 2020

\section{Pembobotan Analytical Hiererchy Process (AHP)}

Perhitungan bobot fungsional dimulai dari sub elemen, elemen, komponen hingga sub komponen bangunan. Pembobotan ini diperlukan untuk menghitung indeks kondisi bangunan. Pembobotan dapat dilakukan dengan metode multi kriteria, yaitu dengan penilaian matriks perbandingan berpasangan (pairwise comparison matrix) berdasar metode AHP dengan input utamanya persepsi manusia, dimana secara naluri manusia dapat mengestimasi besaran sederhana melalui inderanya. Saaty (1991) menetapkan skala kuantitatif 1 (satu) sampai dengan 9 (sembilan) untuk menilai perbandingan tingkat kepentingan suatu elemen terhadap yang lain, seperti ditunjukkan pada Tabel 3.

Tabel 3. Skala Penilaian Perbandingan Pasangan

\begin{tabular}{cll}
\hline $\begin{array}{c}\text { Intensitas } \\
\text { Kepentingan }\end{array}$ & \multicolumn{1}{c}{ Keterangan } & \multicolumn{1}{c}{ Penjelasan } \\
\hline $\mathbf{1}$ & $\begin{array}{l}\text { Kedua elemen sama } \\
\text { pentingnya }\end{array}$ & $\begin{array}{l}\text { Dua elemen mempunyai } \\
\text { pengaruh yang sama besar } \\
\text { terhadap tujuan }\end{array}$ \\
\hline $\mathbf{3}$ & $\begin{array}{l}\text { Elemen yang satu sedikit } \\
\text { lebih penting daripada elemen } \\
\text { yang lainnya }\end{array}$ & $\begin{array}{l}\text { Pengalaman dan penilaian sedikit } \\
\text { menyokong satu elemen } \\
\text { dibandingkan elemen lainnya }\end{array}$ \\
\hline $\mathbf{5}$ & $\begin{array}{l}\text { Elemen yang satu lebih } \\
\text { penting daripada elemen yang } \\
\text { lainnya }\end{array}$ & $\begin{array}{l}\text { Pengalaman dan penilaian sangat } \\
\text { kuat menyokong satu elemen } \\
\text { dibanding elemen lainnya }\end{array}$ \\
\hline $\mathbf{7}$ & $\begin{array}{l}\text { Satu elemen sangat jelas lebih } \\
\text { mutklak penting daripada } \\
\text { elemen lainnya }\end{array}$ & $\begin{array}{l}\text { Satu elemen yang kuat dikosong } \\
\text { dan dominan terlihat dalam }\end{array}$ \\
& $\begin{array}{l}\text { Satu elemen mutlak penting } \\
\text { daripada elemen lainnya }\end{array}$ & $\begin{array}{l}\text { Bukti yang mendukung elemen } \\
\text { yang satu terhadap elemen lain } \\
\text { memiliki tingkat penegasan } \\
\text { tertinggi yang mungkin menguat }\end{array}$ \\
\hline $\mathbf{9}$ & $\begin{array}{l}\text { Nilai ini diberikan bila ada dua } \\
\text { kompromi diantara dua pilihan }\end{array}$ \\
\hline $\mathbf{2 , 4 , 6 , 8}$ & $\begin{array}{l}\text { Nilai-nilai antara dua nilai } \\
\text { pertimbangan-pertimbangan } \\
\text { yang berdekatan }\end{array}$ \\
\hline Kebalikan & $\begin{array}{l}\text { Jika untuk aktifitas i mendapat satu angka dibanding dengan } \\
\text { aktifitas j, maka j mempunyai nilai kebalikannya dibandng dengan } \\
\text { i }\end{array}$ \\
\hline Sumber: Saaty 1991
\end{tabular}


JURNAL KACAPURI

JURNAL KEILMUAN TEKNIK SIPIL

Volume 3 Nomor 2 Edisi Desember 2020

\section{METODE PENELITIAN}

\section{Lokasi Penelitian}

Waduk Tirtomarto atau lebih dikenal dengan nama Waduk Delingan dibangun oleh Pemerintah Belanda mulai tahun 1920 dan selesai pada tahun 1923. Secara administratif waduk tersebut terletak di Kelurahan Delingan, Kecamatan Karanganyar, Kabupaten Karanganyar, kira-kira 30 $\mathrm{km}$ sebelah timur Kota Solo Jawa Tengah. Untuk menuju lokasi waduk bisa ditempuh dengan roda empat selama kurang lebih 30 menit dari Kota Solo Jawa Tengah. Lokasi penelitian terdapat dalam Gambar 1.

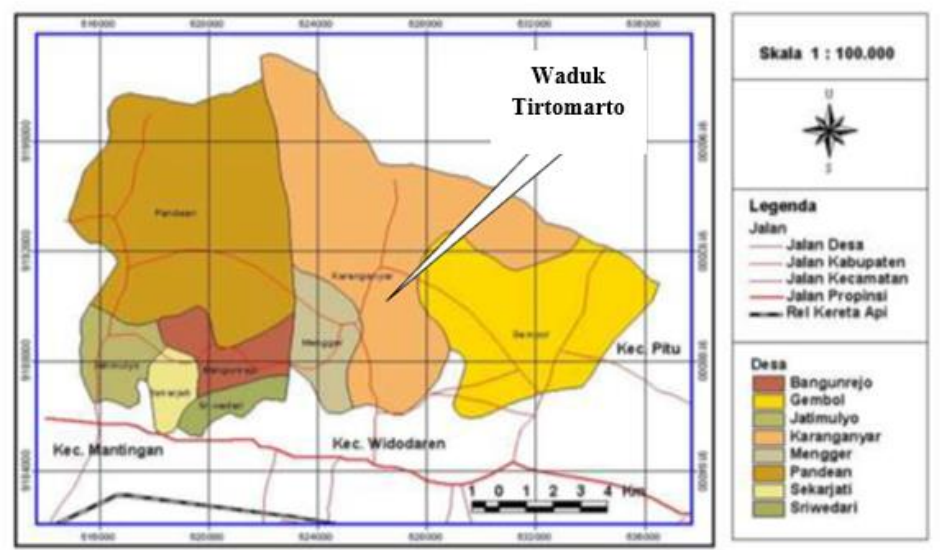

Gambar 1. Lokasi Penelitian

\section{Parameter dan Variabel}

Parameter dan variabel yang digunakan dalam penelitian ini disajikan dalam Tabel 4.

Tabel 4. Parameter Penelitian

\begin{tabular}{|c|c|c|c|}
\hline NO & URAIAN & $\begin{array}{l}\text { KETERKAITAN } \\
\text { ANALISIS }\end{array}$ & $\begin{array}{l}\text { SUMBER } \\
\text { DATA }\end{array}$ \\
\hline I & Parameter dalam Penelitian & & \\
\hline 1 & Data Inventaris Bendungan & Inventarisasi & Data Sekunder \\
\hline 2 & $\begin{array}{l}\text { Data Kondisi Komponen } \\
\text { Bendungan }\end{array}$ & Kondisi Fisik dan Fungsi & Data Primer \\
\hline II & Variabel dalam Penelitian & & \\
\hline 1 & Bobot Penilaian & $\begin{array}{l}\text { Bobot yang Diberikan } \\
\text { Setiap Komponen }\end{array}$ & Data Primer \\
\hline 2 & $\begin{array}{l}\text { Jenis dan Tingkat } \\
\text { Kerusakan }\end{array}$ & Penentuan Kerusakan & Data Primer \\
\hline 3 & $\begin{array}{l}\text { Penilaian Kondisi } \\
\text { Bendungan }\end{array}$ & $\begin{array}{l}\text { Penilaian dari Fisik dan } \\
\text { Fungsi Setiap Komponen }\end{array}$ & Data Primer \\
\hline
\end{tabular}


JURNAL KACAPURI

JURNAL KEILMUAN TEKNIK SIPIL

Volume 3 Nomor 2 Edisi Desember 2020

\section{Data dan Sumber Data}

\section{Data Primer}

Data primer diperoleh dengan melakukan pengamatan dan survei lokasi, adapun data yang diperlukan adalah sebagai berikut:

a. Pengukuran jenis kerusakan dan dimensi kerusakan komponen bendungan,

b. Dokumentasi setiap komponen bendungan,

c. Studi kepustakaan yaitu melakukan pencarian sumber informasi yang diperlukan, baik dari instansi, buku literatur, jurnal, dan situs web internet.

2. Data Sekunder

Data sekunder diperoleh dari instansi yang terkait, dalam hal ini adalah dari Balai Besar Wilayah Sungai Bengawan Solo. Data sekunder yang diperlukan dalam penelitian ini adalah Inventarisasi komponen Waduk Tirtomarto.

\section{Tahapan Penelitian}

Tahapan Penelitian ditunjukkan dalam Gambar 2.

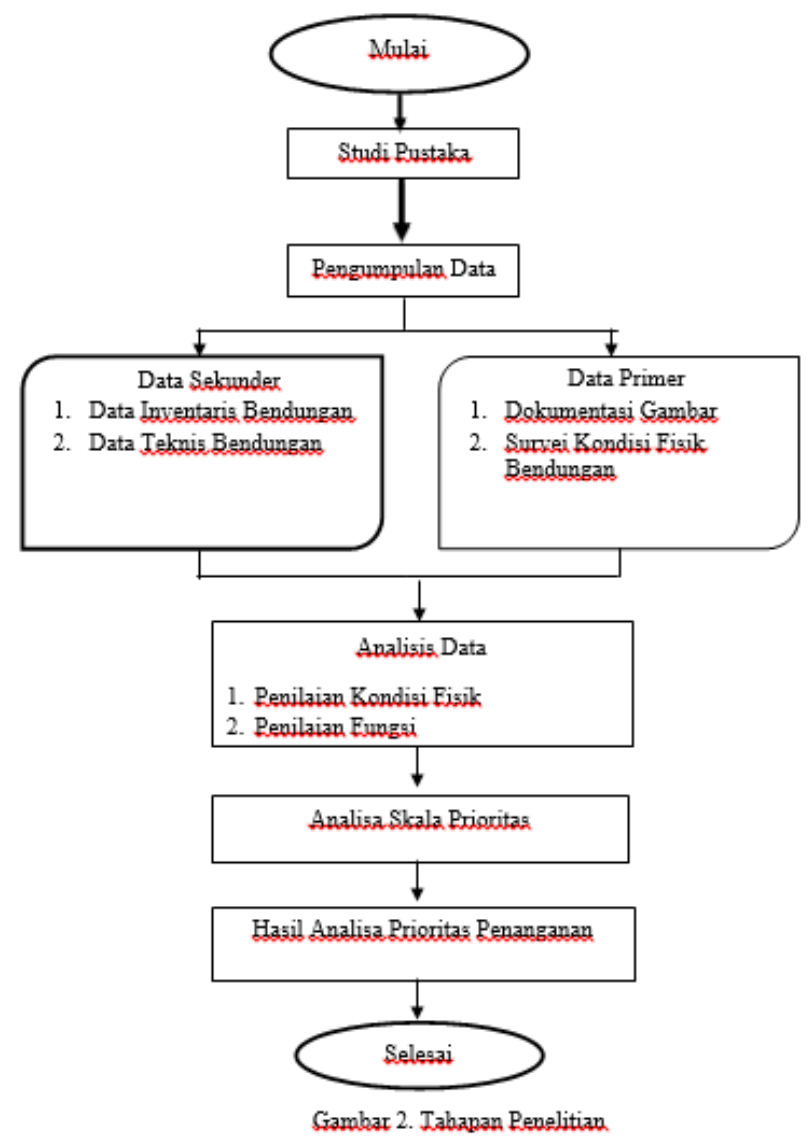


JURNAL KACAPURI

JURNAL KEILMUAN TEKNIK SIPIL

Volume 3 Nomor 2 Edisi Desember 2020

\section{HASIL DAN PEMBAHASAN}

\section{Perhitungan Penilaian Kondisi Fisik Waduk Tirtomarto}

Dari data-data pemeriksaan baik secara langsung atau pun tidak langsung kemudian data-data tersebut digabung dan diproses untuk mendapatkan penilaian kondisi bendungan yang diinginkan. Hasil Penilaian kondisi fisik Waduk Tirtomarto tahun 2019 disajikan dalam Tabel 4.

Tabel 4. Penilaian Kondisi Fisik Waduk Tirtomarto Tahun 2019

DAFTAR PENILAIAN KONDISI FISIK WADUK TIRTOMARTO KABUPATEN KARANGANYAR TAHUN 2019

\begin{tabular}{|c|c|c|c|c|c|}
\hline \multirow[b]{2}{*}{ No } & \multirow[b]{2}{*}{ NAMA BANGUNAN } & \multirow[b]{2}{*}{$\begin{array}{c}\text { Nilai Bobot } \\
(\%)\end{array}$} & \multicolumn{2}{|c|}{ Nilai Prestasi } & \multirow[b]{2}{*}{ Keterangan } \\
\hline & & & $\begin{array}{l}\text { NKF } \\
(\%)\end{array}$ & $\begin{array}{l}\text { NKB } \\
(\%)\end{array}$ & \\
\hline 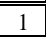 & 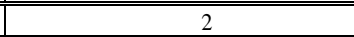 & 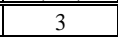 & 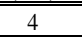 & $5=(3 \times 4)$ & 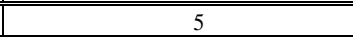 \\
\hline \multirow[t]{5}{*}{$\mathbf{I}$} & WADUK & 10,00 & & 9,15 & NKF $=$ Nilai Kondisi Fisik \\
\hline & 1) Sedimentasi & 3,00 & 90,00 & 2,70 & NKB $=$ Nilai Kondisi Bobot \\
\hline & 2) Sabuk hijau & 3,00 & 91,00 & 2,73 & 1. Kondisi Baik, jika : \\
\hline & 3) Inflow & 4,00 & 93,00 & 3,72 & Nilai Kondisi $>90-100 \%$ dan \\
\hline & & & & & Nilai Tingkat Kerusakan $<10 \%$ \\
\hline \multirow[t]{7}{*}{ II } & TUBUH BENDUNGAN & 40,00 & & 37,60 & 2. Kondisi Rusak Ringan, jika : \\
\hline & 1) Lereng Hulu & 10,00 & 95,00 & 9,50 & Nilai Kondisi 80 - $90 \%$, dan nilai \\
\hline & 2) Puncak & 10,00 & 93,00 & 9,30 & \\
\hline & 3) Lereng Hilir & 10,00 & 95,00 & 9,50 & \\
\hline & 4) Bidang Tumpuan & 5,00 & 91,00 & 4,55 & \\
\hline & 5) Rembesan & 5,00 & 95,00 & 4,75 & 3. Kondisi Rusak Sedang, jika : \\
\hline & & & & & Nilai kondisi $60-79 \%$, dan nilai \\
\hline \multirow[t]{6}{*}{ III } & BANGUNAN PELENGKAP & 40,00 & & 37,20 & Tingkat Kerusakan $21-40 \%$ \\
\hline & 1) Bangunan Pengambilan & 10,00 & 90,00 & 9,00 & \\
\hline & 2) Bangunan Pengeluaran & 10,00 & 96,00 & 9,60 & 4. Kondisi Rusak Berat, jika : \\
\hline & 3) Bangunan Pelimpah & 15,00 & 94,00 & 14,10 & Apabila bagian bangunan tidak ada, \\
\hline & 4) Gardu Pandang & 5,00 & 90,00 & 4,50 & \\
\hline & & & & & bangunan lain sesuai urgensinya \\
\hline \multirow[t]{6}{*}{ IV } & INSTRUMENTASI WADUK & 10,00 & & 8,74 & \\
\hline & 1) Instrumen pengukur rembesan & 3,00 & 96,00 & 2,88 & \\
\hline & 2) Instrumen pengukur tekanan pori & 3,00 & 91,00 & 2,73 & \\
\hline & 3) Instrumen pengukur pergerakan & 3,00 & 95,00 & 2,85 & \\
\hline & 4) Instrument Stasiun Hujan & 0,70 & 95,00 & 0,67 & \\
\hline & 5) Instrument Pengukur Muka Air & 0,30 & 93,00 & 0,28 & \\
\hline & JUMLAH NILAI & 100,00 & - & 92,69 & \\
\hline
\end{tabular}

Kondisi Baik -Rewak Ringan-Rusak Sedang - Rusak Berat

Sumber: Analisa 
JURNAL KACAPURI

JURNAL KEILMUAN TEKNIK SIPIL

Volume 3 Nomor 2 Edisi Desember 2020

Setelah didapatkan penilain-penilan pada tiap sub komponen dari Bendungan Delingan, penilaian tersebut diakumulasikan pada tiap sub komponen dari Bendungan Delingan, dan mendapatkan nilai kondisi fisik sebagai berikut:
a) Kondisi waduk
$: 9,15$
b) Tubuh bendungan
$: 37,60$
c) Bangunan pelengkap
$: 37,20$
d) Instrumentasi waduk
$: 8,74$
Dengan jumlah total keseluruhan
$: 92,69$

Hasil penilaian kondisi Bendungan Delingan tersebut didapatkan hasil 92,69\%, dengan hasil tersebut maka kondisi Bendungan Delingan pada Tahun 2019 dinyatakan dalam kondisi Baik (nilai kondisi $>90-100 \%$ dan tingkat kerusakan $<10 \%$ (diperlukan pemeliharaan rutin). Dari perhitungan nilai kondisi komponen tersebut dapat dijadikan grafik kondisi waduk seperti pada Gambar 3.

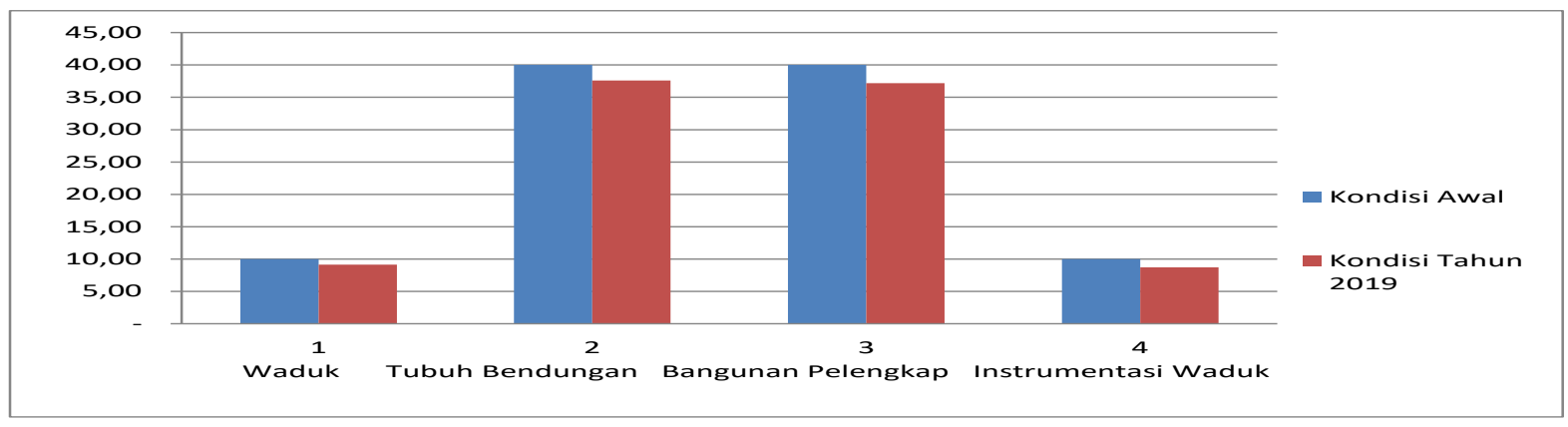

Gambar 3. Grafik Kondisi Fisik Waduktirto Tahun 2019

\section{Skala Prioritas dengan aplikasi Analytical Hierarchy Process}

1. Pembobotan Kondisi Fisik Waduk Tirtomarto

Pembobotan kondisi fisik ini dihitung berdasarkan penilaian kondisi fisik Waduk Tirtomarto tahun 2019. Untuk lebih jelas terdapat dalam Tabel 5.

Tabel 5. Kondisi Fisik Waduk Tirtomarto

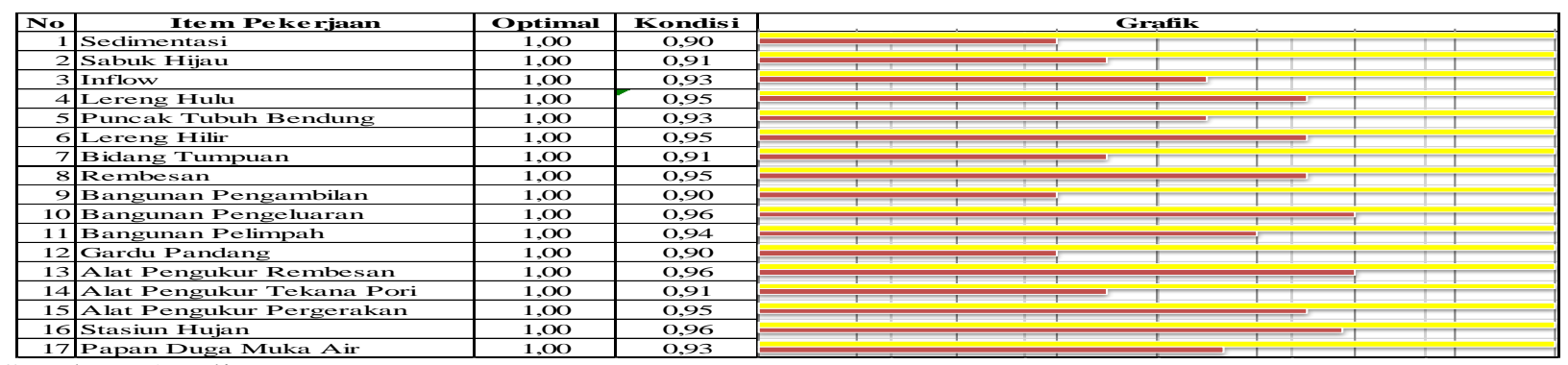

Sumber: Analisa 
JURNAL KACAPURI

JURNAL KEILMUAN TEKNIK SIPIL

Volume 3 Nomor 2 Edisi Desember 2020

Terlihat bahwa bangunan pengambilan memiliki kondisi fisik yang paling rendah sehingga memerlukan prioritas penanganan utama, sedangkan kondisi fisik yang terbaik adalah lereng hilir.

\section{Pembobotan Prioritas Penanganan}

Pada pembobotan prioritas penanganan ini digunakan Analytical Hierarchy Process Method (AHP) untuk perhitungannya. Proses ini digunakan karena dianggap dapat mewakili dari keseluruhan aspek yang dihitung untuk mendapatkan prioritas penanganannya. Pertama-tama adalah membandingkan mana yang penting, lebih penting dan tidak penting. Perbandingan ini dilakukan untuk mendapatkan angka koefisien sebagai dasar penentuan prioritas menggunakan AHP. Dengan menggunakan angka perbandingan tingkat kepentingan, terdapat dalam Tabel 6.

Tabel 6. Nilai Tingkat Keterpentingan

\begin{tabular}{|c|c|c|c|c|c|c|c|c|c|c|c|c|c|c|c|c|c|c|}
\hline \multirow{3}{*}{\begin{tabular}{|c|} 
FAKTOR \\
$\mathrm{C} 1$ \\
\end{tabular}} & \multicolumn{17}{|c|}{ SKOR BOBOT FAKTOR } & \multirow{3}{*}{\begin{tabular}{|c} 
FAKTOR \\
$\mathrm{C} 2$
\end{tabular}} \\
\hline & \multicolumn{8}{|c|}{ LEBIH PENTING DARI } & SAMA & \multicolumn{8}{|c|}{ KURANG PENTING DARI } & \\
\hline & 9 & 8 & 7 & 6 & 5 & 4 & 3 & 2 & 1 & 2 & 3 & 4 & 5 & 6 & 7 & 8 & 9 & \\
\hline $\mathrm{C} 2$ & 9 & 8 & 7 & 6 & 5 & 4 & 3 & 2 & 1 & 2 & 3 & 4 & 5 & 6 & 7 & 8 & 9 & $\mathrm{C} 3$ \\
\hline $\mathrm{C} 3$ & 9 & 8 & 7 & 6 & 5 & 4 & 3 & 2 & 1 & 2 & 3 & 4 & 5 & 6 & 7 & 8 & 9 & $\mathrm{C} 4$ \\
\hline $\mathrm{C} 4$ & 9 & 8 & 7 & 6 & 5 & 4 & 3 & 2 & 1 & 2 & 3 & 4 & 5 & 6 & 7 & 8 & 9 & $\mathrm{C} 5$ \\
\hline C5 & 9 & 8 & 7 & 6 & 5 & 4 & 3 & 2 & 1 & 2 & 3 & 4 & 5 & 6 & 7 & 8 & 9 & C6 \\
\hline C6 & 9 & 8 & 7 & 6 & 5 & 4 & 3 & 2 & 1 & 2 & 3 & 4 & 5 & 6 & 7 & 8 & 9 & $\mathrm{C} 7$ \\
\hline C7 & 9 & 8 & 7 & 6 & 5 & 4 & 3 & 2 & 1 & 2 & 3 & 4 & 5 & 6 & 7 & 8 & 9 & $\mathrm{C} 8$ \\
\hline $\mathrm{C} 8$ & 9 & 8 & 7 & 6 & 5 & 4 & 3 & 2 & 1 & 2 & 3 & 4 & 5 & 6 & 7 & 8 & 9 & C9 \\
\hline C9 & 9 & 8 & 7 & 6 & 5 & 4 & 3 & 2 & 1 & 2 & 3 & 4 & 5 & 6 & 7 & 8 & 9 & $\mathrm{C} 10$ \\
\hline $\mathrm{C} 10$ & 9 & 8 & 7 & 6 & 5 & 4 & 3 & 2 & 1 & 2 & 3 & 4 & 5 & 6 & 7 & 8 & 9 & $\mathrm{C} 11$ \\
\hline C11 & 9 & 8 & 7 & 6 & 5 & 4 & 3 & 2 & 1 & 2 & 3 & 4 & 5 & 6 & 7 & 8 & 9 & $\mathrm{C} 12$ \\
\hline $\mathrm{C} 12$ & 9 & 8 & 7 & 6 & 5 & 4 & 3 & 2 & 1 & 2 & 3 & 4 & 5 & 6 & 7 & 8 & 9 & $\mathrm{C} 13$ \\
\hline $\mathrm{C} 13$ & 9 & 8 & 7 & 6 & 5 & 4 & 3 & 2 & 1 & 2 & 3 & 4 & 5 & 6 & 7 & 8 & 9 & $\mathrm{C} 14$ \\
\hline $\mathrm{C} 14$ & 9 & 8 & 7 & 6 & 5 & 4 & 3 & 2 & 1 & 2 & 3 & 4 & 5 & 6 & 7 & 8 & 9 & $\mathrm{C} 15$ \\
\hline C15 & 9 & 8 & 7 & 6 & 5 & 4 & 3 & 2 & 1 & 2 & 3 & 4 & 5 & 6 & 7 & 8 & 9 & C16 \\
\hline C16 & 9 & 8 & 7 & 6 & 5 & 4 & 3 & 2 & 1 & 2 & 3 & 4 & 5 & 6 & 7 & 8 & 9 & $\mathrm{C} 17$ \\
\hline
\end{tabular}

Sumber: Analisa

Dengan nilai tingkat kepentingan dilakukan perbandingan berpasangan antar komponen yang satu dengan yang lainnya mulai dari prioritas pertama dibandingkan dengan prioritas kedua dan seterusnya sampai prioritas terakhir. Hal yang sama juga dilakukan dengan membandingkan peringkat kedua dengan peringkat ketiga dan seterusnya sampai peringkat terakhir, hal ini dilakukan sampai dengan semua alternatif telah dibandingkan satu dengan yang lainnya. Setelah dibandingkan berpasangan dilakukan, pada Tabel 7 dapat dilihat hasil rekapan dari perbandingan berpasangan antar alternatif-alternatif yang telah dibandingkan. 
JURNAL KACAPURI

JURNAL KEILMUAN TEKNIK SIPIL

Volume 3 Nomor 2 Edisi Desember 2020

Tabel 7. Perbandingan Pasangan Alternatif

\begin{tabular}{|c|c|c|c|c|c|c|c|c|c|c|c|c|c|c|c|c|c|}
\hline KRITERIA & C1 & $\mathrm{C} 2$ & $\mathrm{C} 3$ & $\mathrm{C} 4$ & $\mathrm{C} 5$ & C6 & $\mathrm{C7}$ & $\mathrm{C} 8$ & $\mathrm{CP}$ & C10 & C11 & C12 & C13 & C14 & C15 & C16 & C17 \\
\hline $\mathrm{C} 1$ & 1.00 & 0.33 & 1.00 & 3.00 & 0.20 & 3.00 & 3.00 & 0.14 & 3.00 & 3.00 & 1.00 & 0.14 & 0.33 & 1.00 & 0.20 & 0.33 & 0.20 \\
\hline $\mathrm{C} 2$ & 3.00 & 1.00 & 5.00 & 7.00 & 3.00 & 7.00 & 5.00 & .00 & 5.00 & 5.00 & 3.00 & 0.33 & 3.00 & 5.00 & 1.00 & 3.00 & 1.00 \\
\hline C3 & 1.00 & 0.20 & 1.00 & 3.00 & 0.33 & 3.00 & 3.00 & 0.20 & 3.00 & 3.00 & 3.00 & 0.20 & 0.20 & 1.00 & 0.20 & 0.33 & 0.20 \\
\hline $\mathrm{C} 4$ & 0.33 & 0.14 & 0.33 & 1.00 & 0.33 & 1.00 & 1.00 & 0.14 & 1.00 & 1.00 & 0.33 & 0.14 & 0.20 & 1.00 & 0.33 & 0.20 & 0.20 \\
\hline C5 & 5.00 & 0.33 & 3.00 & 3.00 & 1.00 & 3.00 & 3.00 & 0.20 & 3.00 & 3.00 & 3.00 & 0.20 & 0.20 & 1.00 & 0.20 & 0.33 & 0.20 \\
\hline C6 & 0.33 & 0.14 & 0.33 & 1.00 & 0.33 & 1.00 & 1.00 & 0.14 & 1.00 & 1.00 & 0.33 & 0.14 & 0.20 & 1.00 & 0.33 & 0.20 & 0.20 \\
\hline C7 & 0.33 & 0.20 & 0.33 & 1.00 & 0.33 & 1.00 & 1.00 & 0.14 & 1.00 & 1.00 & 0.33 & 0.14 & 0.20 & 1.00 & 0.33 & 0.20 & 0.20 \\
\hline $\mathrm{C} 8$ & 7.00 & 1.00 & 5.00 & 7.00 & 5.00 & 7.00 & 7.00 & 1.00 & 0.33 & 0.33 & 0.33 & 0.14 & 0.20 & 1.00 & 0.33 & 0.20 & 0.20 \\
\hline C9 & 0.33 & 0.20 & 0.33 & 1.00 & & & & 3.00 & 1.00 & 1.00 & & & 0.20 & 1.00 & 33 & 20 & 0.20 \\
\hline C10 & 0.33 & 0.20 & 0.33 & 1.00 & 0.33 & 1.00 & 1.00 & 3.00 & 1.00 & 1.00 & 0.33 & 0.14 & 0.20 & 1.00 & 0.33 & 0.20 & 0.20 \\
\hline C11 & 1.00 & 0.33 & 0.33 & 3.00 & 0.33 & 3.00 & 3.00 & 3.00 & 3.00 & 3.00 & 1.00 & 0.14 & 0.20 & 1.00 & 0.33 & 0.20 & 0.20 \\
\hline C12 & 7.00 & 3.00 & 5.00 & 7.00 & 5.00 & 7.00 & 7.00 & 7.00 & 7.00 & 7.00 & 7.00 & 1.00 & 5.00 & 7.00 & 3.00 & 5.00 & 3.00 \\
\hline C13 & 3.00 & 0.33 & 5.00 & 5.00 & 5.00 & 5.00 & 5.00 & 5.00 & 5.00 & 5.00 & 5.00 & 0.20 & 1.00 & 3.00 & 0.33 & 0.20 & 0.33 \\
\hline C14 & 1.00 & 0.20 & 1.00 & 1.00 & 1.00 & 1.00 & 1.00 & 1.00 & 1.00 & 1.00 & 1.00 & 0.14 & 0.33 & 1.00 & 0.20 & 3.00 & 0.20 \\
\hline C15 & 5.00 & 1.00 & 5.00 & 3.00 & 5.00 & 3.00 & 3.00 & 3.00 & 3.00 & 3.00 & 3.00 & 0.33 & 3.00 & 5.00 & 1.00 & 3.00 & 1.00 \\
\hline C16 & 3.00 & 0.33 & 3.00 & 5.00 & 3.00 & 5.00 & 5.00 & 5.00 & 5.00 & 5.00 & 5.00 & 0.20 & 5.00 & 0.33 & 0.33 & 1.00 & 0.33 \\
\hline C17 & 5.00 & 1.00 & 5.00 & 5.00 & 5.00 & 5.00 & 5.00 & 5.00 & 5.00 & 5.00 & 5.00 & 0.33 & 3.00 & 5.00 & 1.00 & 3.00 & 1.00 \\
\hline TOTAL & 43.67 & 9.95 & 41.00 & 57.00 & 35.53 & 57.00 & 55.00 & 37.97 & 48.33 & 48.33 & 39.00 & 4.09 & 22.47 & 36.33 & 9.80 & 20.60 & 8.87 \\
\hline
\end{tabular}

Sumber: Hasil Analisa

Setelah mendapatkan angka koefisien yang dibutuhkan kemudian angka koefisien tersebut dimasukkan kedalam tabel normalisasi untuk kemudian dihitung CI dan ditentukan RI-nya. Perlu diketahui untuk hasil CI harus mendekati angka 0, sedangkan R1 ditentukan dengan melihat berpa jumlah dari variabel yang dimasukkan. Setelah didapatkan kemudian dilanjutkan menghitung CR sebagai tolok ukur dalam menyelesaikan AHP ini. Perhitungan tersebut ditunjukkan dalam Tabel 8.

Tabel 8. Normalisasi Alternatif

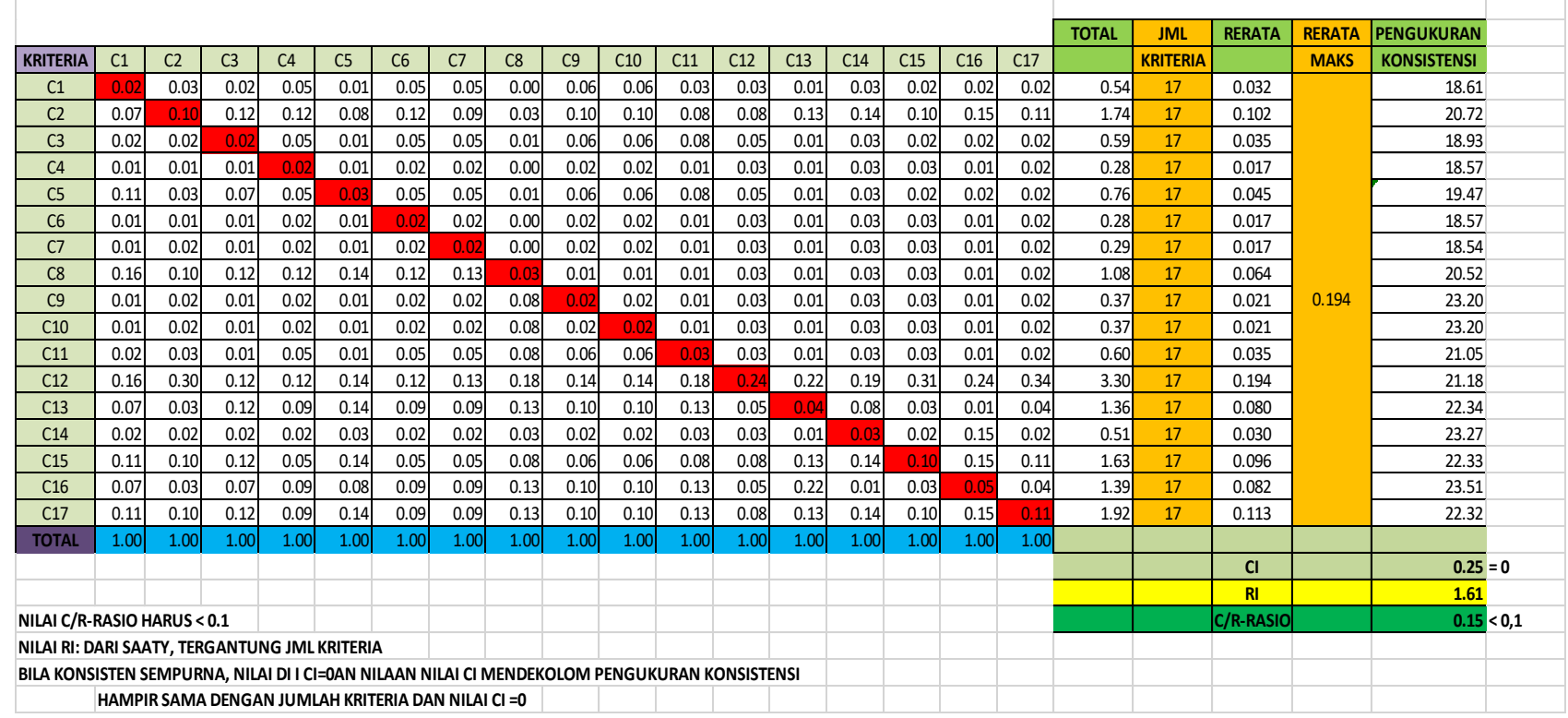

Sumber: Hasil Analisa 
JURNAL KACAPURI

JURNAL KEILMUAN TEKNIK SIPIL

Volume 3 Nomor 2 Edisi Desember 2020

Angka CR yang didapatkan harus memenuhi syarat yaitu CR $<0,1$. Dalam perhitungan Tabel 4.13. Normalisasi angka $\mathrm{CR}$ yang didapatkan adalah 0,06, dimama 0,06 adalah lebih kecil dari 0,1 (memenuhi). Dengan menggunakan metode ini didapatkan hasil prioritas penanganan berdasarkan proritas kepentingan komponen. Dari sini dapat dilihat bahwa prioritas penanganan yang diutamakan atau dianggap penting dari keseluruhan komponen adalah bangunan pengambilan.

\section{Penyelesaian Menggunakan Pogram Expert Choice 11}

Pada penelitian ini menggunakan program Expert Choice 11 sebagai alat untuk menentukan keputusan. Dalam menggunakan program ini hampir sampai dengan penggunaan AHP yang mengkriteriakan dan menggolongkan sesuai yang diinginkan dengan Alternatif-alternatif pilihan yang telah ada. Sebelum menggunakan program ini ditetapkan dulu goal yang akan diinginkan dan kriteria priotitas yang akan digunakan. Kiteria-kriteria yang diambil adalah performa waduk, keamanan waduk, biaya pemeliharaan komponen waduk, tingkat kerusakan komponen waduk dan keterpentingan fungsi komponen waduk. Hasil dari aplikasi Expert Choice tersaji dalam Gambar 4.
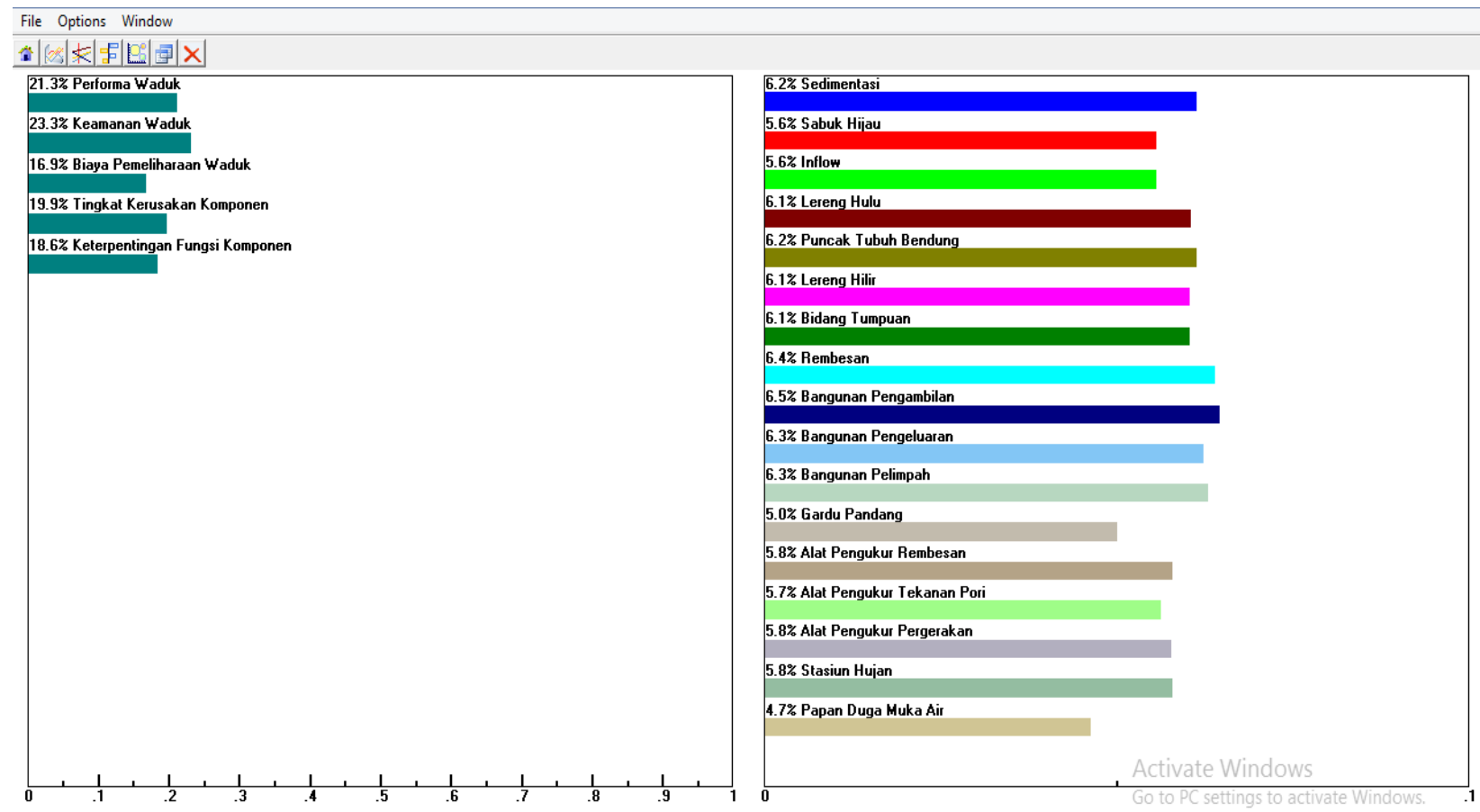

Gambar 4. Sensitivity Grahps - Dynamic 
JURNAL KACAPURI

JURNAL KEILMUAN TEKNIK SIPIL

Volume 3 Nomor 2 Edisi Desember 2020

Dari analisa program Expert Choice 11 pada Gambar 4 didapatkan hasil mengenai prioritas penanganan pemeliharaan berdasarkan performa waduk, keamanan waduk, biaya pemeliharaan waduk, tingkat kerusakan waduk, dan keterpentingan fungsi komponennya. Dari Gambar 4 dapat dilihat bahwa prioritas penanganan pemeliharaan Bendungan Delingan yang didapat dari program Expert Choice 11 adalah bangunan pengambilan. Bangunan Pengambilan menempati peringkat teratas dari hasil analisa program Expert Choice 11, berdasarkan kriteria-kriteria yang telah ditetapkan. Penanganan pemeliharaan bangunan pengambilan sebagai prioritas utama diharapkan dapat menjadikan kinerja Waduk Tirtomarto dapat optimal.

\section{PENUTUP}

\section{Kesimpulan}

Hasil analisis terhadap penentuan skala prioritas pemeliharaan kondisi fisik Waduk Tirtomarto dengan apikasi analitical hierarchy project dan expert choice 11 didapatkan hasil Waduk Tirtomarto pada tahun 2019 dinyatakan dalam kondisi Baik. Analisa aplikasi Analytical Hierarchy Process dan Expert Choice 11 juga didapatkan prioritas penanganan pemeliharaan Waduk Tirtomarto adalah bangunan pengambilan. Bangunan Pengambilan menempati peringkat teratas dari hasil analisa program berdasarkan kriteria-kriteria yang telah ditetapkan. Penanganan pemeliharaan bangunan pengambilan sebagai prioritas utama diharapkan dapat menjadikan kinerja Waduk Tirtomarto dapat optimal.

\section{Saran}

Saran-saran yang dapat disampaikan adalah Standar penilaian kondisi fisik bendungan belum ada penilaian aspek partisipasi masyarakat. Oleh karena itu dapat dikembangkan penilaian kondisi fisik bendungan yang memasukkan aspek partisipasi masyarakat dan standar penilaian kondisi fisik bendungan belum semua komponen dianalisis secara kuantitatif. Oleh karena itu bisa dikembangkan sebuah penilaian yang lebih banyak analisa kuantitatifnya untuk mengurangi subyektifitas. 


\section{DAFTAR PUSTAKA}

1. Anonim, 2010, Peraturan Pemerintah Nomor 37 Tahun 2010, Tentang Bendungan, Kementerian Pekerjaan Umum, Jakarta.

2. Donny Adzan. M, dkk, 2008, Kritisnya Kondisi Bendungan Di Indonesia, Seminar Komite Nasional Indonesia untuk Bendungan Besar (KNI-BB), Surabaya 2-3 Juli 2008.

3. Herlen, 2009, Pengelolaan Bendungan PLTA PB. SOEDIRMAN, Seminar Komite Nasional Indonesia untuk Bendungan Besar (KNI-BB), Yogyakarta 10-11 Juni 2009

4. Prasetya Kurniawan, Edwin.2016. Prioritas Perbaikan Saluran Drainase Dengan Metode Analytic Network Process (ANP) Di Kelurahan Kadipiro Bagian Barat. Jurnal. Surakarta: Fakultas Teknik Sipil, Universitas Sebelas Maret

5. M. Marzulian Ramli dan Bambang E. Yuwono, 2015, Identifikasi Faktor Dominan Pengelolaan Waduk Yang Berberpengaruh Terhadap Kinerja Waduk, Seminar Nasional Teknik Sipil V Tahun 2015 -UMS

6. Saaty, T. L., 1996, Decision Making with Dependence and Feedback-The Analytical Hierarchy Process, RWS Publications, Pittsburgh 